\title{
Math in Brazil: Sowing the Seeds
}

\author{
Marcelo Viana
}

Brazil is soon to host the first International Congress of Mathematicians ever to be held in the Southern Hemisphere, ICM 2018. About a year before that, Rio de Janeiro will also be the stage for the first International Mathematical Olympiad to happen in the country, IMO 2017. Taking advantage of this circumstance, the mathematical community is promoting the Biennium of Mathematics 2017-2018, a broad and ambitious initiative sponsored by the National Congress to disseminate and popularize mathematics in the whole society-children and their families, students and their teachers.

All this pays tribute to the remarkable development experienced by Brazilian mathematics over the last decades. And none of it could have been foreseen only a generation ago, back in 1986 when I joined IMPA-Instituto de Matemática Pura e Aplicada for grad school. Back then,

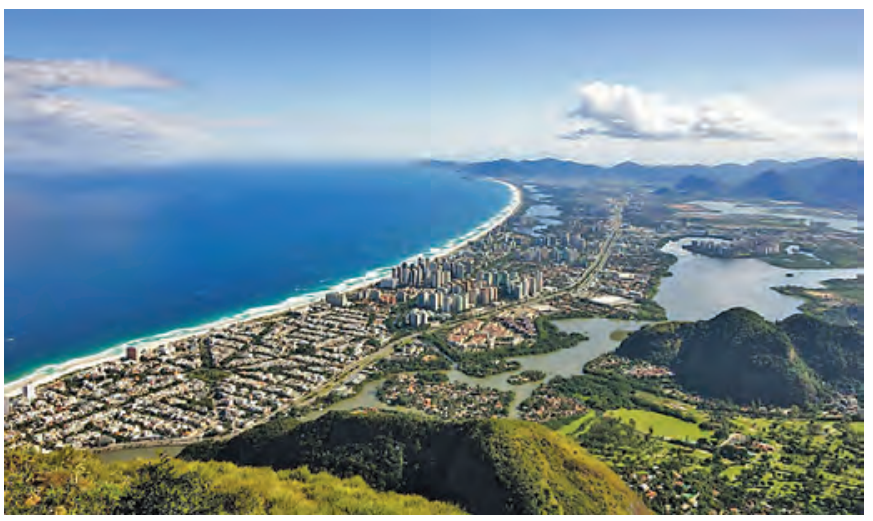

Figure 1. Rio de Janeiro will host the International Mathematical Olympiad in 2017 and the International Congress of Mathematicians in 2018.

Marcelo Viana is director of IMPA. His e-mail address is viana@ impa.br.

For permission to reprint this article, please contact:

reprint-permission@ams.org.

DOI: http://dx.doi.org/10.1090/noti1481

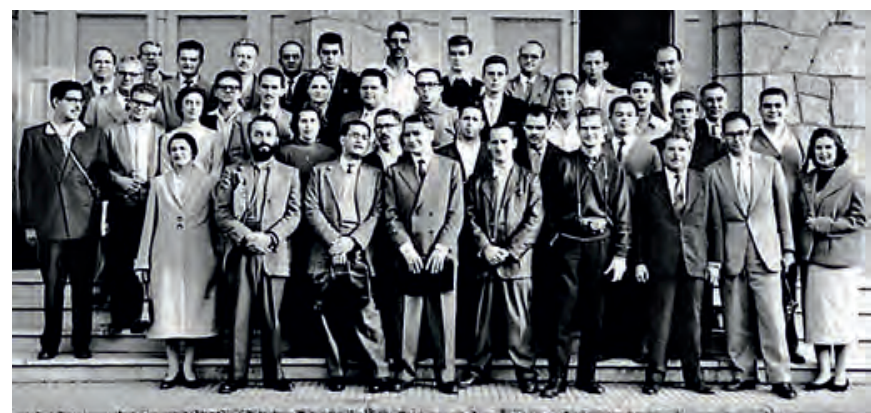

Figure 2. The first Brazilian Mathematical Colloquium was held in 1957.

should anyone have told us that in less than three decades a young Brazilian raised and educated in the country would win the Fields Medal, we would all have smiled in utter disbelief. Except, perhaps, for then seven-year-old Artur Avila himself.

Because the fact is that mathematics, and science in general, in Brazil is a very young idea. Brazilians love to blame it on the kings of Portugal. The conventional story goes that a jealous colonial power, eager to prevent the development and spread of "subversive ideas," forbade the printing and circulation of journals and newspapers, thus hampering the development of a knowledgeable society. A more nuanced truth is that many such policies remained in place after independence under the two emperors and, to a lesser extent, even after the republic had replaced the monarchy. As a result, most scientific institutions were created rather late. Besides, not surprisingly, the earlier ones were concerned with such issues as tropical diseases, sanitation, and public health. Mathematics was not a priority at that stage.

The first person to go on record as a mathematical researcher was Joaquim Gomes de Souza, born in 1829 in the northeastern state of Maranhão. After getting a degree from the Military School in Rio de Janeiro, the only institution in the country offering higher education in mathematics, Souza traveled to Paris, where he presented his 
mathematical papers to the Académie des Sciences. Deeply disappointed with the lack of response (the committee, chaired by Cauchy, never even met), Souza returned to his country, quit mathematics for politics and poetry, and died at the age of thirty-five, leaving no academic heirs.

Another century would pass before regular activities in mathematics could take off in the 1950s. That is when Brazil joined the IMU (International Mathematical Union), the Brazilian Mathematical Colloquium was first held (see Figure 2), and a number of important institutions were founded, including IMPA. By then a network of public universities was in place around the country, most notably the University of São Paulo and the University of Brazil in Rio de Janeiro. Leopoldo Nachbin and Mauricio Peixoto graduated in engineering from the latter and went on to co-found IMPA and to be the first Brazilian mathematicians giving invited addresses at the ICM in 1962 and 1974 , respectively.

The contribution of Brazilian mathematicians to the ICMs has become more and more regular, with a current total of three plenary lectures and fourteen invited addresses. A record was broken in Seoul 2014 with one plenary (Fernando Codá Marques) and three invited speakers (in dynamics, geometry, and probability).

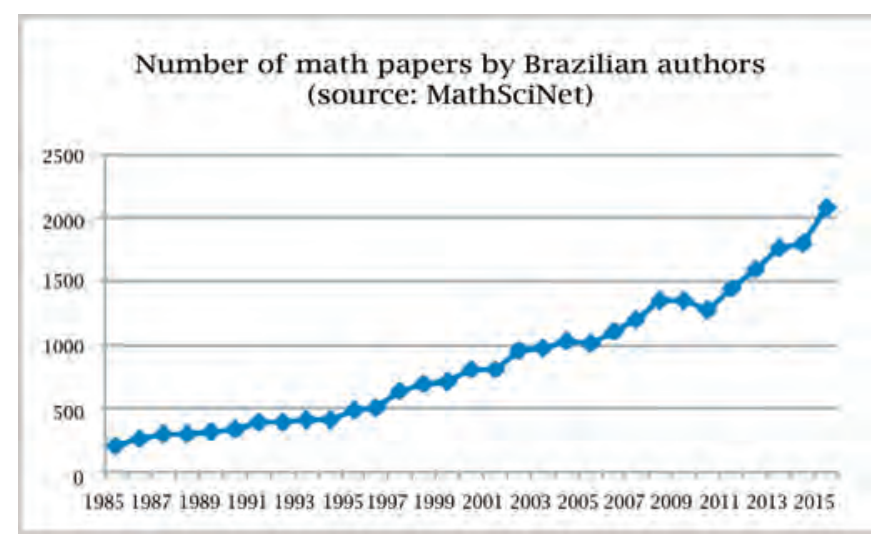

Table 1. The number of mathematics papers by Brazilian authors has risen from 255 in 1985 to 2,076 in 2015.

Percentage of math papers by Brazilian authors (source: MathSciNet)

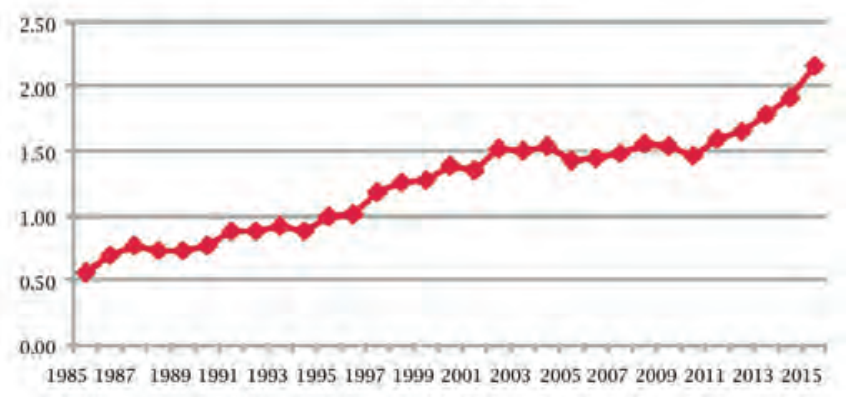

Table 2. The percentage of mathematics papers by Brazilian authors has risen from a half percent in 1985 to over 2 percent today.

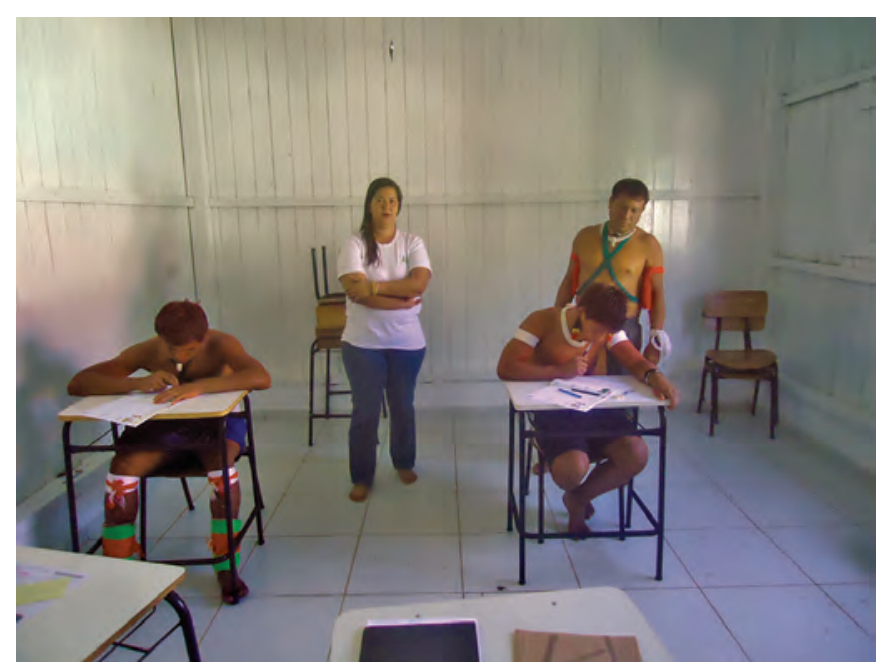

Figure 3. Students of the indigenous school Tuparã, at Nova Ubiratã, state of Mato Grosso, participating in the 2015 Mathematical Olympiad.

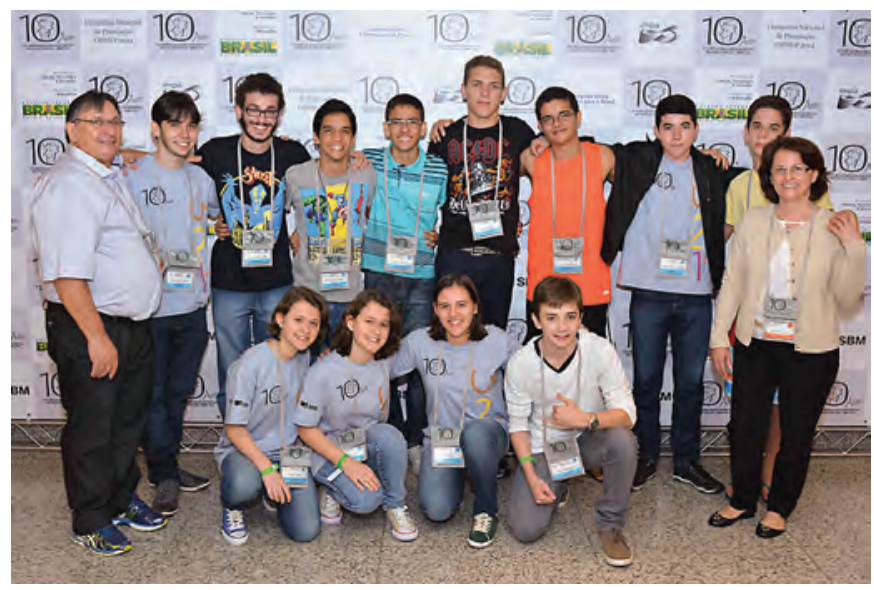

Figure 4. Students participating in the 2014 Mathematical Olympiad: in the front row, triplets and gold medalists Fabia, Fabiele, and Fabiola Monteiro.

All this reflects the rapid growth of mathematical research that is so clearly displayed in Tables 1 and 2: Brazil now accounts for about 2.1 percent of the world's total production. As a comparison, both the GDP and the population of Brazil are around 2.9 percent of the world's total.

There are now nearly sixty graduate programs in mathematics and statistics. They train an increasing number of Brazilian students and a substantial number of foreigners, especially from Latin America and, increasingly, Asia, Europe, and North America. A major concern is that, despite steady growth, the total number of doctoral degrees granted in mathematics and statistics every year (about 180 currently) still falls short of the needs presented by Brazil's expanding university system, not to mention industry. The difficulty in attracting good graduate students is also a reflection of deeper problems in basic education.

Indeed, official data about the performance of students in elementary, middle, and high schools just released by the Ministry of Education show that, while there has been 


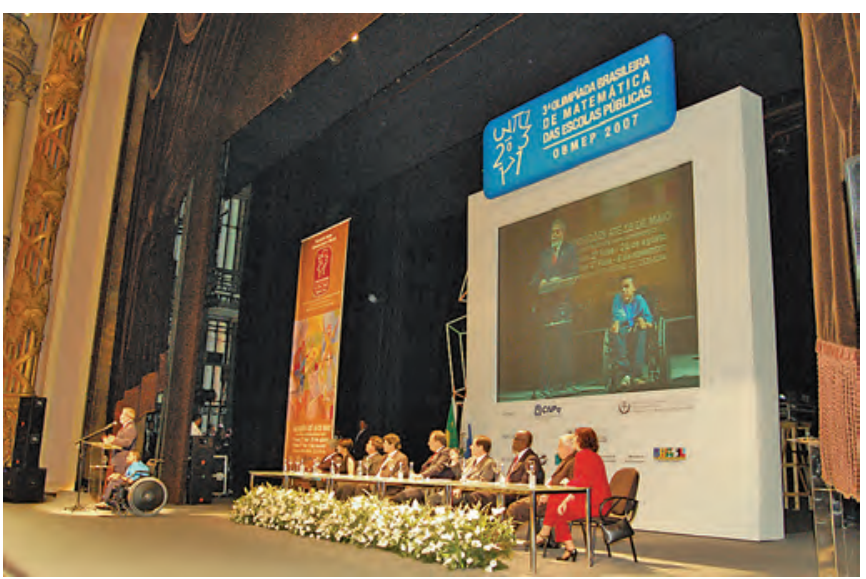

Figure 5. At the 2007 Mathematical Olympiad award ceremony, Brazil president Lula pays tribute to Ricardo Oliveira, a survivor of spinal amyotrophy, who was carried to school in a wheelbarrow and went on to win a gold medal. Ricardo will soon graduate in industrial mechatronics.

some improvement in early years, progress at the high school level has stalled. Results in the PISA (Programme for International Student Assessment), an international performance test held every third year for fifteen-year-old students, are equally unflattering. Despite some modest progress, Brazil still performs well below the OECD (Organization for Economic Cooperation and Development) average. In fact, in 2012 Brazil ranked 58th among the 65 countries taking the test. These facts prompted the federal government to propose a reform of high school education, which is currently being discussed in Congress.

The SBM (Brazilian Mathematical Society) was founded in 1969. Other mathematical societies have been established since: the Brazilian Society for Applied and Computational Mathematics (SBMAC), the Brazilian Statistics Association, the Brazilian Society for Mathematical Education, and the Brazilian Society for the History of Mathematics.

The SBM has about two thousand associates and is a nonprofit publishing house for mathematical books and journals. It also runs several initiatives of broad interest, such as PROFMAT, the nationwide master's program for schoolteachers. PROFMAT operates through a nationwide network of over seventy universities and institutes in all twenty-seven Brazilian states and has already granted Master's degrees to more than 2,600 high school teachers. It is also helping bring universities and schools together for a dialogue that has been missing for decades and is crucial for dealing with the problems of education, especially at the high school level.

Brazil has two major mathematical Olympiads. The OBM (Brazilian Mathematical Olympiad) was created in 1979 at the initiative of the SBM, promoting regional and national mathematical competitions involving about 500,000 students from middle school to college level as well as Brazil's very successful participation in International Mathematical Olympiads.

The OBMEP (Brazilian Mathematical Olympiad for Public Schools) was started by IMPA and the federal government in 2005 and now reaches about eighteen million secondary school students every year. Over little more than a decade, it has become a major event in our academic calendar and one with a particularly high profile. As a sign of its prestige, the award ceremony for the gold medalists is usually chaired by the president of Brazil. Efforts are currently under way to integrate the two competitions more effectively, starting in 2017.

Brazilian mathematics was born open to international cooperation by necessity as much as by design. IMPA keeps a vigorous visitor program totaling over eight hundred visitor-months per year. A highlight is the cycle of meetings run by the SBM and the SBMAC jointly with their counterparts in some of our major partner countries. The first Brazil-Spain meeting was held in Fortaleza in December 2015, and the Brazil-Italy meeting hosted by IMPA in August 2016 was also remarkably successful. Preparations for the Brazil-France meeting in 2019 are well advanced. The idea of a joint meeting with the United States in 2020 has been floated, and conversations were initiated with our Portuguese colleagues, having in mind that 2022 will mark the 200th anniversary of Brazil's independence from Portugal.

Preparations for the ICM 2018 and the IMO 2017, as well as for the IMU General Assembly 2018, in São Paulo, are well under way.

Rio de Janeiro has gotten used to hosting major international events: the 2013 Catholic Journey of Youth,

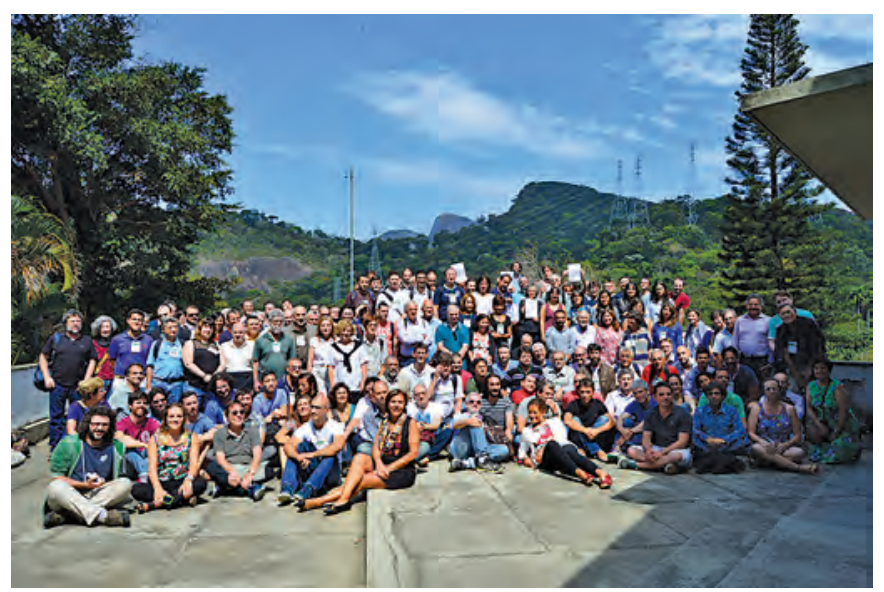

Figure 6. Around 300 mathematicians attended the Brazil-Italy joint meeting at IMPA in August 2016. 


\section{COMMUNICATION}

the 2014 FIFA World Cup, and the 2016 Olympic and Paralympic Games, just to mention the largest ones. Major infrastructure was overhauled in several parts of town, most especially in the western neighborhood of Barra da Tijuca, pictured in Figure 1, where ICM 2018 will take place. Barra da Tijuca was a major site for the Olympic Games and now boasts over 12,000 hotel rooms and a brand-new transportation system.

Following a rough year in 2015 and despite an economic situation that remains adverse, the general mood in Brazil has been improving substantially as the country's political and economic troubles seem to be subsiding. Both the achievements of Brazilian mathematicians and the shortcomings of mathematical education in the country regularly put mathematics in the headlines, which makes the timing for the upcoming IMO and ICM especially fortunate. All this makes me confident that we will have a great Biennium of Mathematics 2017-2018 and that it will sow the seeds of a new era for mathematics in Brazil. I'm really looking forward to the official launching of the Biennium at the first Brazilian Math Festival, April 27-30, 2017. Check out the website †estivaldamatematica. org.br and come participate!

\section{Photo Credits}

Figure 1 is courtesy of the ICM2018 Organizing Committee.

Figures 2, and 6, as well as Marcelo Viana's photo are courtesy of IMPA.

Figures 3, 4, and 5 are courtesy of IMPA/OBMEP.

Tables 1 and 2 are courtesy of MathSciNet.

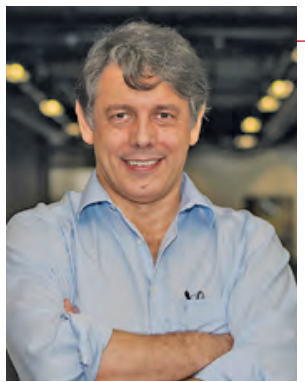

Marcelo Viana

\section{ABOUT THE AUTHOR}

Marcelo Viana, director of IMPA, received the inaugural ICTP Ramanuident of the Brazilian Mathematical Society from 2013 to 2015. Being a father of two (six and nine) is reintroducing him to mathematics from a whole new angle. jan Prize in 2005 and served as pres-
American Mathematical Society

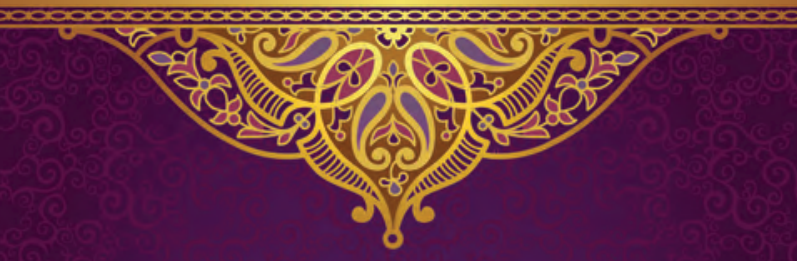

FEATURED TITLES FROM 几口冋 HINDUSTAN $\square \square$ BOOK AGENCY

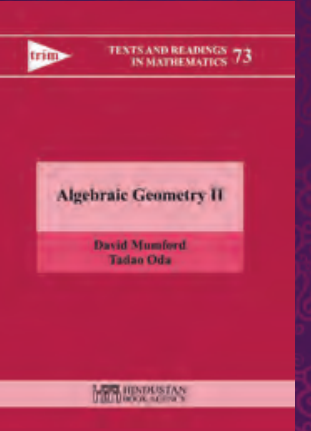

$$
\begin{aligned}
& \text { ALGEBRAIC } \\
& \text { GEOMETRY II } \\
& \text { David Mumford, Brown } \\
& \text { University, Providence, RI, and } \\
& \text { Tadao Oda, Tohoku University, } \\
& \text { Japan } \\
& \text { Several generations of students of } \\
& \text { algebraic geometry have learned } \\
& \text { the subject from David Mumford's } \\
& \text { fabled "Red Book," which con- } \\
& \text { tains notes of his lectures at } \\
& \text { Harvard University. Their genesis } \\
& \text { and evolution are described by } \\
& \text { Mumford in the preface. }
\end{aligned}
$$

20I5; 5 I6 pages; Hardcover; ISBN: 978-93-80250-80-9; List US\$76; AMS members US $\$ 60.80$; Order code HIN/70

OPERATORS ON

HILBERT SPACE

V. S. Sunder, Institute of

Mathematical Sciences, Chennai, India

This book's principal goals are: (i) to present the spectral theorem as a statement on the existence of a unique continuous and measurable functional calculus, (ii) to present a proof without digressing into a course on the Gelfand theory of commutative Banach algebras, (iii) to introduce the reader to the basic facts concerning the various von NeumannSchatten ideals, the compact operators, the trace-class operators and all bounded operators, and finally, (iv) to serve as a primer on the theory of bounded linear operators on separable Hilbert space.

2015; I 10 pages; Softcover; ISBN: 978-93-80250-74-8; List US\$40; AMS members US\$32; Order code HIN/69

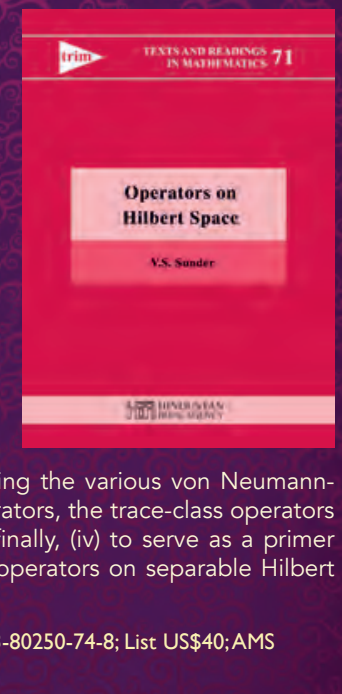

VIEW MORE TITLES AT BOOKSTORE.AMS.ORG/HIN

Publications of Hindustan Book Agency are distributed within the Americas by the American Mathematical Society. Maximum discount of 20\% for commercial channels.

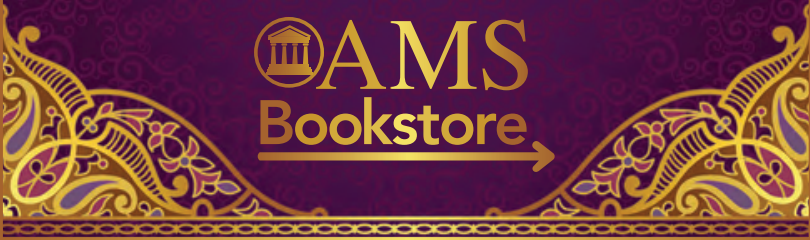

